\title{
Review Article \\ Transcriptional Regulators of Claudins in Epithelial Tight Junctions
}

\author{
Niamat Khan ${ }^{1,2}$ and Abdul R. Asif ${ }^{1}$ \\ ${ }^{1}$ Institute for Clinical Chemistry/UMG-Laboratories, University Medical Center Göttingen, Robert-Koch-Straße 40, \\ 37075 Göttingen, Germany \\ ${ }^{2}$ Department of Biotechnology \& Genetic Engineering, Kohat University of Science and Technology, Kohat 26000, \\ Khyber Pakhtunkhwa, Pakistan \\ Correspondence should be addressed to Abdul R. Asif; asif@med.uni-goettingen.de
}

Received 13 June 2014; Revised 22 September 2014; Accepted 3 October 2014

Academic Editor: H. Barbaros Oral

Copyright ( 2015 N. Khan and A. R. Asif. This is an open access article distributed under the Creative Commons Attribution License, which permits unrestricted use, distribution, and reproduction in any medium, provided the original work is properly cited.

Human gastrointestinal tract is covered by a monolayer of specialized epithelial cells that constitute a protective barrier surface to external toxic and infectious agents along with metabolic and digestive functions. Intercellular junctions, among epithelial cells, such as desmosomes, adherens, gap, and tight junctions (TJs), not only provide mechanical integrity but also limit movement of molecules across the monolayer. TJ is a complex structure composed of approximately 35 different proteins that interact with each other at the apical side of two adjacent epithelial cells. Claudin family proteins are important members of TJ with so far 24 known isoforms in different species. Claudins are structural proteins of $\mathrm{TJ}$ that help to control the paracellular movement by forming fence and barrier across the epithelial monolayer. Altered function of claudins is implicated in different form of cancers, inflammatory bowel diseases (IBDs), and leaky diarrhea. Based on their significant role in the molecular architecture of TJ, diversity, and disease association, further understanding about claudin family proteins and their genetic/epigenetic regulators is indispensable.

\section{Introduction}

Epithelial monolayer (EM) is the largest body tissue lining many organs in the human body. In the intestine, EM provides protection to the internal body from toxic and infectious agents while at the same time it facilitates absorption of digested food and water from the gut. Epithelial monolayer integrity and paracellular transport are the important features that can be protected and maintained with the help of epithelial barrier function [1]. Epithelial cells are connected with each other by four types of junctions, that is, desmosomes, gap junctions, adherens junctions, and TJs [2-4]. Tight junctions are impermeable and control the movement of molecules and ions via a paracellular pathway. Until recently, tight junction functions were categorized as "fence" as they separate the apical and basolateral cell surface domain defining cell polarity or a "barrier" due to their control over solutes and liquid flow through the paracellular space between the epithelial cells [5-8]. However TJs are not restricted to the fence and barrier function but have been defined to participate in signal transduction processes, gene expression, cell proliferation, and differentiation [9-11]. Various unidentified external and internal regulators impair the normal function of TJs causing loss of water and solute in the passive manner that leads to leaky-flux watery diarrhea. The unwanted invasion of noxious luminal antigens prolongs the existence of mucosal inflammatory processes [12].

Tight junction (TJ) is a complex structure constituting of growing numbers of components, including integral membrane proteins (claudins, occludin, and junctional adhesion molecules "JAMs") and peripheral membrane proteins. The peripheral membrane proteins include (1) scaffold PDZ (postsynaptic density protein (PSD95), Drosophila discs large tumor suppressor (Dlg1), and Zonula occludens-1 protein (ZO-1)), multi-PDZ domain protein-1 (MUPP-1), and membrane-associated guanylate kinase (MAGI-1); (2) no-PDZ expressing proteins such as cingulin, symplekin, 
atypical protein kinase C, Ras-related protein Rab-3B (Rab3b), Ras-related protein Rab-13 (Rab-13), phosphatase and tensin homolog (PTEN), and 7H6 antigen; (3) cell polarity molecules ASIP/PAR-3, partitioning defective 6 homolog alpha (PAR-6), and PALS1-associated TJ protein (PATJ) [13, 14]. Besides these proteins, tricellulin protein has recently been identified at the epithelial cell junctions with involvement in the barrier function [15].

Claudin family so far includes 24 reported members in different types of mammalian cells; among them 21 are known components of $\mathrm{TJ}$ in EM in the kidneys, liver, brain, and intestine [25]. These are involved in various physiological processes such as regulation of paracellular permeability and conductance. Claudins are found in homo and heterotypic manner in single TJ $[13,26]$. They can be divided into two main categories, "pore-sealing" and pore-forming claudins. Claudin- $-1,-3,-4,-5,-7$, and -19 are known as pore-sealing claudins and an increased expression of these claudin proteins leads to increased tightness of EM and increased transepithelial electrical resistance (TEER) and decreases solute permeability across the monolayer [27-31]. On the other hand, claudin-2 and -15 are considered as the "pore-forming claudins," because of their ability to form paracellular anion/cation pores as well as water channels and therefore they decrease epithelial tightness and increase solute permeability $[13,32]$.

Epithelial barrier dysfunctions occur in inflammatory bowel diseases (IBDs) like Crohn's disease (CD) or ulcerative colitis (UC) that contribute to leaky-flux diarrhea, that is, loss of solutes and water in increased amount dependent upon the components of TJ proteins. Downregulation of pore-sealing claudins (e.g., 4, 5, and 8) while upregulation of pore-forming claudin-2 is observed in active Crohn's disease patients [33, 34]. Similarly downregulation of pore-sealing claudin-4 is also associated with UC disease [34]. Numerous studies have reported leaky diarrhea in patients undergoing immunosuppressive therapy after organ transplantation [3538]. Recently our group has reported mycophenolic acid(MPA-) mediated increased expression of myosin light chain kinase (MLCK), myosin light chain-2 (MLC-2), and MLC-2 phosphorylation and redistribution of $\mathrm{ZO}-1$ and occludin in Caco-2 and in HEK-293 cells $[39,40]$ as a possible mechanism of diarrhea in patients undergoing immunosuppressive therapy. Transcription factors (TFs) play an important role in the gene regulation at the promoter level working either as an activator or as a repressor of a specific gene. The current review will focus major claudins family members (Table 1) and their regulators, which alter claudins gene activity at promoter level and therefore modulate TJs structure and function.

\section{Claudin-1}

Claudin-1 protein is a key constituent of TJs and its altered expression is reported in a variety of cancers, most prominently colorectal cancers [13, 17, 41, 42]. Promoter region ( -1160 bps to $-850 \mathrm{bps}$ ) of claudin-1 consists of putative binding sites for caudal-related homeobox (cdx-1, -2), GATA4, and T-cell factor/lymphoid enhancing factor-1 (Tcf/Lef-1) transcription factors. There is a direct correlation between claudin-1 and cdx-2 expression in human colon cancer patient [17]. Cdx-2 is a homeobox domain-containing nuclear transcription factor that plays an important role in intestinal development by regulating the proliferation and differentiation of intestinal cells [43-45], and it is expressed in all cells along the crypt villus axis. Cdx-2 transcriptional activity is controlled through mitogen-activated protein kinase/extra cellular signal regulated kinase pathway (MAPK/ERK pathway) which phosphorylates it at ser-60 position and resultantly reduces cdx-2 transcription activity in crypt and lowers villus cells. On the other side, cyclin-dependent kinase 2 (CDK2) phosphorylates cdx-2 at Ser-281 which coordinates $\mathrm{cdx}-2$ polyubiquitination and degradation by the proteasome [43, 46-49].

Specificity protein-1 (Sp-1) is the first identified transcription factor of specificity protein/Krüppel-like factor (Sp/XKLF) family, consisting of 785 amino acids (aa) with molecular weight of 100 to $110 \mathrm{kDa}$. Sp-1's DNA binding domain is the most conserved among other domains of SP family members which consisted of Cy2His2 Zinc (Zn) fingers. Mutational analysis has revealed that $\mathrm{Zn}$ fingers 2 and 3 are essential for DNA binding activity [50]. Sp-1 binds to the GC-rich elements [51] that are common regulatory elements in the promoters of numerous genes. Sp-1 binds its individual binding sites as a multimer and is capable of synergic activation of promoters containing multiple binding sites [52] and regulates transcription by dynamically recruiting and forming complexes with many factors associated with transcription [53]. Normally $\mathrm{Sp}-1$ has been described as a transcriptional activator but it can also act as a repressor [54]. Claudin-1 promoter region ( -138 to $-76 \mathrm{bp}$ ) contains Sp-1 binding site and a mutation in this region results in a significant loss of claudin-1 transcription [16].

\section{Claudin-2}

Claudin-2, also known as leaky protein, forms paracellular water channels in TJs and mediates paracellular transport of water molecules across the EM. EM permeability is enhanced by increased expression of claudin-2 in TJs. It is also involved in many signaling pathways, including vitamin $\mathrm{D}$ receptor, epidermal growth factor receptor (EGFR), and c-Jun Nterminal kinases (JNK) signaling pathways, and contributes to inflammatory bowel disease and colon cancer [33, 5558]. Salmonella infection facilitates bacterial invasion across the EM by inducing claudin-2 expression and altering its localization in TJs which is reversible by specific inhibitors (EGFR (Gefitinib) and JNK (SP600125)), making claudin-2 as a potential therapeutic target to prevent bacterial invasion and inflammation [59].

Interleukin-6 (IL-6) increases TJ permeability of Caco2 monolayer from the basal side by inducing caludin2 expression. IL- 6 activates the mitogen-activated protein kinases/extracellular signal-regulated kinases (MEK/ERK) pathway by inducing phosphorylation of ERK and phosphatidylinositol $3^{\prime}$-kinase (PI3K/Akt) by phosphorylating 
TABLE 1: Regulators of claudins.

\begin{tabular}{lccc}
\hline TJ proteins & Regulator & Promoter binding region & Expression/reference \\
\hline Claudin-1 & Sp-1 & -138 to $-76 \mathrm{bp}$ & $\uparrow[16]$ \\
& $\mathrm{cdx}-2$ & -1160 to $-850 \mathrm{bp}$ & $\uparrow[17]$ \\
Claudin-2 & $\mathrm{cdx}-2$ & -1067 to $-1 \mathrm{bp}$ & $\uparrow[18]$ \\
Claudin-3 & Sp-1 & -112 to $-74 \mathrm{bp}$ & $\uparrow[19]$ \\
Claudin-4 & Sp-1 & -105 to $-49 \mathrm{bps}$ & $\downarrow[20]$ \\
Claudin-5 & FoxO1 & $-2,906$ to $-2,871 \mathrm{bps}$ & $\uparrow[22]$ \\
Claudin-7 & ELF-3 & -150 bps & $\uparrow[23]$ \\
Claudin-15 & Hnf4 $\alpha$ & -693 to $-47 \mathrm{bps}$ & $\uparrow[24]$ \\
Claudin-19 & Sp-1 & -139 to $-75 \mathrm{bps}$ & \\
\hline
\end{tabular}

Note: arrow $(\uparrow)=$ upregulation, arrow $(\downarrow)=$ downregulation.

Akt, which in turn enhances cdx-2 expression. In the claudin2 promoter region ( -1067 to -1 ), four $c d x-2$ (cdx-A, $-B$, $-\mathrm{C}$, and -D), STAT, and nuclear factor-kappa-light-chainenhancer of activated B cells (NF- $\kappa \mathrm{B})$ putative binding sites are identified. IL- 6 induced expression of claudin- 2 can be reversed by using either specific inhibitors of MEK/ERK and PI3K/AKT pathways (U0126 (a MEK inhibitor) and LY294002 (a PI3K inhibitor)) or site directed mutagenesis in the putative $c d x-2$ binding sites in the promoter region of claudin-2 gene [18].

\section{Claudin-3, Claudin-4, and Claudin-5}

Both claudin-3 and claudin-4 are overexpressed in ovarian cancer. A Sp-1 binding site ( -112 and -74 bps) in the promoter region of claudin-3 is crucial for its activation. Claudin-3 expression is significantly decreased at mRNA and protein levels, by knocking down the Sp-1 with siRNA, indicating an essential role of Sp-1 in claudin-3 activation [19]. Claudin4 is mainly expressed in the EM of colon, renal tubules, mammary gland, and thyroid gland and is considerably raised in their cancers [60]. There are two known Sp-1 binding sites (between -105 and $-49 \mathrm{bps}$ ) in the promoter region of claudin-4 [20].

Caludin-5 is mostly expressed in the TJs of EM of pancreatic acinar cells, alveolar lung cells, colon, and endothelial cells forming the blood-brain barrier and endoneurial bloodnerve barrier. In colonic regions, its expression is mainly involved in the paracellular sealing of TJs [33, 61-63]. Both downregulation and redistribution of claudin- 5 can alter TJs structure leading to barrier dysfunction in active Crohn's disease [33]. Forkhead box (foxO) gene family members are potent transcriptional activators with four known members; foxO1 (also known as foxOla), foxO3 (also known as foxO3a), foxO4, and foxO6 which bind to conserved consensus core recognition motif TTGTTTAC [64-66]. Four pairs of putative binding sites for foxO and tcf- $\beta$-catenin (Tcf- $\beta$-catenin act as a stabilizer) are identified in the three regions of claudin-5 promoter (region 1, position -2,906/-2,871; region 2 , position $-2,317 /-2,287$; region 3 , position $-1,103 /-1,008)$. Both foxO1 and tcf- $\beta$-catenin interact with region 1 of the caludin-5 promoter to repress its transcription [21].

\section{Claudin-7}

Claudin-7 is expressed prominently in the biphasic type of synovial sarcoma of adults. E74-like factor 3 (ELF3) belongs to E26 transformation-specific sequence (ETS) family of transcription factors and binds to the Ets binding site in the promoter region ( $-150 \mathrm{bps}$ ) of claudin-7 [22]. Members of ETS family are mainly involved in cell differentiation, proliferation, and cell transformation [67]. Regulation of the target genes by ETS factors depends upon their activation by MAPK and their association with other cofactors [68, 69]. An essential role of ELF3 is reported in epithelial cell differentiation [70-72] and small interference RNA (siRNA) treatment downregulates the claudin-7 expression validating the central role of ELF3 in claudin-7 activation.

\section{Claudin-15}

Claudin-15 is a pore-forming protein expressed in the EM of intestine, liver, and kidney tissues. Downregulation of claudin-15 decreases permeability of EM layer and can initiate IBD. Four putative binding sites (BS1-4) of transcription factor hepatocyte nuclear factor 4 alpha $(\mathrm{hnf} 4 \alpha)$ are present in the ( -693 to $-47 \mathrm{bps}$ ) region of claudin-15 promoter [23]. $\mathrm{Hnf} 4 \alpha$ is considered as an important regulator of EM barrier integrity and is involved in the regulation of metabolism, cell junction, differentiation, and proliferation of liver and intestine epithelial cells [73]. Both animal model and IBD patients' biopsy studies have shown that an altered expression of hnf $4 \alpha$ directly influences the expression and distribution of claudin-15 [23].

\section{Claudin-19}

The kidney is responsible for the filtration of excretory material from the blood. However, $25-40 \%$ of filtered $\mathrm{Na}^{+}$ [74], 50-60\% of filtered $\mathrm{Mg}^{2+}$ [75], and 30-35\% of filtered $\mathrm{Ca}^{2+}[76]$ are reabsorbed into the body by thick ascending limb, the loop of Henle. Claudin-16 and -19 play a main role in the regulation of $\mathrm{Mg}^{2+}$ reabsorption and loss of either claudin-16 or -19 leads to excessive renal waste of $\mathrm{Mg}^{2+}$ [77]. Four putative transcription factor (not characterized, AP2, 
NF-E, and Sp-1) binding sites are located between -139 and -75 in the promoter region of mouse claudin-19. However, only Sp-1 is described for having an important role in the expression of claudin-19 and a mutation in Sp-1 binding site significantly reduces the claudin-19 expression [24].

\section{Conclusion}

Tight junctions play an important role in the regulation of paracellular movement of molecules across the EM, impart mechanical strength, maintain the polarity of cells, and prevent the passage of unwanted molecules and pathogens through the space between the plasma membranes of adjacent cells. The efficiency of the junction in preventing ion passage increases exponentially with the number of strands of claudins family proteins which are having important role in the structure as well as controlling paracellular movement across the tight junctions. Altered expression of claudins family proteins in TJs plays a key role in numerous abnormalities like cancers, IBDs, and leaky diarrhea and a better understanding of their regulatory mechanism could help in designing innovative therapeutic strategies.

\section{Conflict of Interests}

The authors declare that there is no conflict of interests regarding the publication of this paper.

\section{Acknowledgments}

The authors acknowledge the support by the German Research Foundation (DFG) and the Open Access Publication Fund of the University of Göttingen. Niamat Khan is the recipient of a German Academic Exchange Service (DAAD) and Higher Education Commission (HEC) of Pakistan Award.

\section{References}

[1] A. M. Marchiando, W. V. Graham, and J. R. Turner, "Epithelial barriers in homeostasis and disease," Annual Review of Pathology: Mechanisms of Disease, vol. 5, pp. 119-144, 2010.

[2] E. Siljamäki, L. Raiko, M. Toriseva et al., "P38 $\delta$ mitogenactivated protein kinase regulates the expression of tight junction protein ZO-1 in differentiating human epidermal keratinocytes," Archives of Dermatological Research, vol. 306, no. 2, pp. 131-141, 2014.

[3] A. M. Costa, M. Leite, R. Seruca, and C. Figueiredo, "Adherens junctions as targets of microorganisms: a focus on Helicobacter pylori," FEBS Letters, vol. 587, no. 3, pp. 259-265, 2013.

[4] S. H. Hong, G.-Y. Kim, Y.-C. Chang, S.-K. Moon, W.-J. Kim, and Y. H. Choi, "Bufalin prevents the migration and invasion of T24 bladder carcinoma cells through the inactivation of matrix metalloproteinases and modulation of tight junctions," International Journal of Oncology, vol. 42, no. 1, pp. 277-286, 2013.

[5] G. van Meer and K. Simons, "The function of tight junctions in maintaining differences in lipid composition between the apical and the basolateral cell surface domains of MDCK cells," The EMBO Journal, vol. 5, no. 7, pp. 1455-1464, 1986.

[6] M. Cereijido, J. Valdés, L. Shoshani, and R. G. Contreras, "Role of tight junctions in establishing and maintaining cell polarity," Annual Review of Physiology, vol. 60, pp. 161-177, 1998.

[7] E. E. Schneeberger and R. D. Lynch, "Structure, function, and regulation of cellular tight junctions," The American Journal of Physiology_Lung Cellular and Molecular Physiology, vol. 262, no. 6, part 1, pp. L647-L661, 1992.

[8] B. M. Gumbiner, "Breaking through the tight junction barrier," Journal of Cell Biology, vol. 123, no. 6, part 2, pp. 1631-1633, 1993.

[9] S. Tsukita, Y. Yamazaki, T. Katsuno, A. Tamura, and S. Tsukita, "Tight junction-based epithelial microenvironment and cell proliferation," Oncogene, vol. 27, no. 55, pp. 6930-6938, 2008.

[10] K. Matter and M. S. Balda, "Signalling to and from tight junctions," Nature Reviews Molecular Cell Biology, vol. 4, no. 3, pp. 225-236, 2003.

[11] T. Kojima, M. Murata, T. Yamamoto et al., "Tight junction proteins and signal transduction pathways in hepatocytes," Histology and Histopathology, vol. 24, no. 11, pp. 1463-1472, 2009.

[12] H. Schmitz, C. Barmeyer, M. Fromm et al., "Altered tight junction structure contributes to the impaired epithelial barrier function in ulcerative colitis," Gastroenterology, vol. 116, no. 2, pp. 301-309, 1999.

[13] S. Tsukita, M. Furuse, and M. Itoh, "Multifunctional strands in tight junctions," Nature Reviews Molecular Cell Biology, vol. 2, no. 4, pp. 285-293, 2001.

[14] E. E. Schneeberger and R. D. Lynch, "The tight junction: s multifunctional complex," The American Journal of Physiology-Cell Physiology, vol. 286, no. 6, pp. C1213-C1228, 2004.

[15] J. Ikenouchi, M. Furuse, K. Furuse, H. Sasaki, S. Tsukita, and S. Tsukita, "Tricellulin constitutes a novel barrier at tricellular contacts of epithelial cells," Journal of Cell Biology, vol. 171, no. 6, pp. 939-945, 2005.

[16] H.-B. Wang, P.-Y. Wang, X. Wang, Y.-L. Wan, and Y.-C. Liu, "Butyrate enhances intestinal epithelial barrier function via upregulation of tight junction protein claudin-1 transcription," Digestive Diseases and Sciences, vol. 57, no. 12, pp. 3126-3135, 2012.

[17] A. A. Bhat, A. Sharma, J. Pope et al., "Caudal homeobox protein Cdx-2 cooperates with Wnt pathway to regulate claudin-1 expression in colon cancer cells," PLOS ONE, vol. 7, no. 6, Article ID e37174, 2012.

[18] T. Suzuki, N. Yoshinaga, and S. Tanabe, "Interleukin-6 (IL-6) regulates claudin-2 expression and tight junction permeability in intestinal epithelium," The Journal of Biological Chemistry, vol. 286, no. 36, pp. 31263-31271, 2011.

[19] H. Honda, M. J. Pazin, T. D’Souza, H. Ji, and P. J. Morin, "Regulation of the CLDN3 gene in ovarian cancer cells," Cancer Biology \& Therapy, vol. 6, no. 11, pp. 1733-1742, 2007.

[20] H. Honda, M. J. Pazin, H. Ji, R. P. Wernyj, and P. J. Morin, "Crucial roles of Spl and epigenetic modifications in the regulation of the cldn 4 promoter in ovarian cancer cells," Journal of Biological Chemistry, vol. 281, no. 30, pp. 21433-21444, 2006.

[21] A. Taddei, C. Giampietro, A. Conti et al., "Endothelial adherens junctions control tight junctions by VE-cadherin-mediated upregulation of claudin-5," Nature Cell Biology, vol. 10, no. 8, pp. 923-934, 2008.

[22] Y. Kohno, T. Okamoto, T. Ishibe et al., "Expression of claudin7 is tightly associated with epithelial structures in synovial sarcomas 
and regulated by an Ets family transcription factor, ELF3," Journal of Biological Chemistry, vol. 281, no. 50, pp. 38941-38950, 2006.

[23] M. Darsigny, J.-P. Babeu, A.-A. Dupuis et al., "Loss of hepatocyte-nuclear-factor- $4 \alpha$ affects colonic ion transport and causes chronic inflammation resembling inflammatory bowel disease in mice," PLoS ONE, vol. 4, no. 10, Article ID e7609, 2009.

[24] J. M. Luk, M.-K. Tong, B. W. Mok, P.-C. Tam, W. S. B. Yeung, and K.-F. Lee, "Sp1 site is crucial for the mouse claudin-19 gene expression in the kidney cells," FEBS Letters, vol. 578, no. 3, pp. 251-256, 2004.

[25] Y. H. Loh, A. Christoffels, S. Brenner, W. Hunziker, and B. Venkatesh, "Extensive expansion of the claudin gene family in the teleost fish, Fugu rubripes," Genome Research, vol. 14, no. 7, pp. 1248-1257, 2004.

[26] M. Furuse, M. Hata, K. Furuse et al., "Claudin-based tight junctions are crucial for the mammalian epidermal barrier: a lesson from claudin-1-deficient mice," Journal of Cell Biology, vol. 156, no. 6, pp. 1099-1111, 2002.

[27] G. Krause, L. Winkler, C. Piehl, I. Blasig, J. Piontek, and S. L. Müller, "Structure and function of extracellular claudin domains," Annals of the New York Academy of Sciences, vol. 1165, pp. 34-43, 2009.

[28] S. S. Oliveira and J. A. Morgado-Diaz, "Claudins: multifunctional players in epithelial tight junctions and their role in cancer," Cellular and Molecular Life Sciences, vol. 64, no. 1, pp. 17-28, 2007.

[29] J. Hou, A. S. Gomes, D. L. Paul, and D. A. Goodenough, "Study of claudin function by RNA interference," The Journal of Biological Chemistry, vol. 281, no. 47, pp. 36117-36123, 2006.

[30] M. D. Alexandre, B. G. Jeansonne, R. H. Renegar, R. Tatum, and Y.-H. Chen, "The first extracellular domain of claudin-7 affects paracellular Cl-permeability," Biochemical and Biophysical Research Communications, vol. 357, no. 1, pp. 87-91, 2007.

[31] R. Tatum, Y. Zhang, K. Salleng et al., "Renal salt wasting and chronic dehydration in claudin-7-deficient mice," The American Journal of Physiology—Renal Physiology, vol. 298, no. 1, pp. F24F34, 2010.

[32] R. Rosenthal, S. Milatz, S. M. Krug et al., "Claudin-2, a component of the tight junction, forms a paracellular water channel," Journal of Cell Science, vol. 123, part 11, pp. 1913-1921, 2010.

[33] S. Zeissig, N. Bürgel, D. Günzel et al., "Changes in expression and distribution of claudin 2, 5 and 8 lead to discontinuous tight junctions and barrier dysfunction in active Crohn's disease," Gut, vol. 56, no. 1, pp. 61-72, 2007.

[34] P. Das, P. Goswami, T. K. Das et al., "Comparative tight junction protein expressions in colonic Crohn's disease, ulcerative colitis, and tuberculosis: a new perspective," Virchows Archiv, vol. 460, no. 3, pp. 261-270, 2012.

[35] E. B. Rangel, C. S. Melaragno, J. R. Sá et al., "Mycophenolate mofetil versus enteric-coated mycophenolate sodium after simultaneous pancreas-kidney transplantation," Transplantation Proceedings, vol. 41, no. 10, pp. 4265-4269, 2009.

[36] P. Darji, R. Vijayaraghavan, C. M. Thiagarajan et al., "Conversion from mycophenolate mofetil to enteric-coated mycophenolate sodium in renal transplant recipients with gastrointestinal tract disorders," Transplantation Proceedings, vol. 40, no. 7, pp. 2262-2267, 2008.

[37] J. A. Moro, L. Almenar, L. Martínez-Dolz, I. Sánchez-Lázaro, J. Agüero, and A. Salvador, "Tolerance profile of the proliferation signal inhibitors everolimus and sirolimus in heart transplantation," Transplantation Proceedings, vol. 40, no. 9, pp. 3034-3036, 2008.

[38] J. D. Pirsch, J. Miller, M. H. Deierhoi, F. Vincenti, and R. S. Filo, "A comparison of tacrolimus (FK506) and cyclosporine for immunosuppression after cadaveric renal transplantation," Transplantation, vol. 63, no. 7, pp. 977-983, 1997.

[39] M. Qasim, H. Rahman, R. Ahmed, M. Oellerich, and A. R. Asif, "Mycophenolic acid mediated disruption of the intestinal epithelial tight junctions," Experimental Cell Research, vol. 322, no. 2, pp. 277-289, 2014.

[40] M. Qasim, H. Rahman, M. Oellerich, and A. R. Asif, "Differential proteome analysis of human embryonic kidney cell line (HEK-293) following mycophenolic acid treatment," Proteome Science, vol. 9, article 57, 2011.

[41] S. Tsukita and M. Furuse, "The structure and function of claudins, cell adhesion molecules at tight junctions," Annals of the New York Academy of Sciences, vol. 915, pp. 129-135, 2000.

[42] P. Dhawan, A. B. Singh, N. G. Deane et al., "Claudin-1 regulates cellular transformation and metastatic behavior in colon cancer," Journal of Clinical Investigation, vol. 115, no. 7, pp. 17651776, 2005.

[43] D. G. Silberg, G. P. Swain, and P. G. Traber, "Cdx1 and Cdx2 expression during intestinal development," Gastroenterology, vol. 119, no. 4, pp. 961-971, 2000.

[44] E. van den Akker, S. Forlani, K. Chawengsaksophak et al., "Cdx1 and Cdx2 have overlapping functions in anteroposterior patterning and posterior axis elongation," Development, vol.129, no. 9, pp. 2181-2193, 2002.

[45] K. Chawiengsaksophak, R. James, V. E. Hammond, F. Köntgen, and F. Beck, "Homeosis and intestinal tumours in Cdx2 mutant mice," Nature, vol. 386, no. 6620, pp. 84-87, 1997.

[46] R. James and J. Kazenwadel, "Homeobox gene expression in the intestinal epithelium of adult mice," Journal of Biological Chemistry, vol. 266, no. 5, pp. 3246-3251, 1991.

[47] M. Houde, P. Laprise, D. Jean, M. Blais, C. Asselin, and N. Rivard, "Intestinal epithelial cell differentiation involves activation of p38 mitogen-activated protein kinase that regulates the homeobox transcription factor CDX2," Journal of Biological Chemistry, vol. 276, no. 24, pp. 21885-21894, 2001.

[48] E. H. H. M. Rings, F. Boudreau, J. K. Taylor, J. Moffett, E. R. Suh, and P. G. Traber, "Phosphorylation of the serine 60 residue within the Cdx2 activation domain mediates its transactivation capacity," Gastroenterology, vol. 121, no. 6, pp. 1437-1450, 2001.

[49] J. Boulanger, A. Vézina, S. Mongrain et al., "Cdk2-dependent phosphorylation of homeobox transcription factor CDX2 regulates its nuclear translocation and proteasome-mediated degradation in human intestinal epithelial cells," Journal of Biological Chemistry, vol. 280, no. 18, pp. 18095-18107, 2005.

[50] J. Song, H. Ugai, K. Ogawa et al., “Two consecutive zinc fingers in Sp1 and in MAZ are essential for interactions with ciselements," Journal of Biological Chemistry, vol. 276, no. 32, pp. 30429-30434, 2001.

[51] S. Philipsen and G. Suske, "A tale of three fingers: the family of mammalian Sp/XKLF transcription factors," Nucleic Acids Research, vol. 27, no. 15, pp. 2991-3000, 1999.

[52] I. A. Mastrangelo, A. J. Courey, J. S. Wall, S. P. Jackson, and P. V. C. Hough, "DNA looping and Spl multimer links: a mechanism for transcriptional synergism and enhancement," Proceedings of the National Academy of Sciences of the United States of America, vol. 88, no. 13, pp. 5670-5674, 1991. 
[53] L. Li, S. He, J.-M. Sun, and J. R. Davie, "Gene regulation by Sp1 and Sp3," Biochemistry and Cell Biology, vol. 82, no. 4, pp. 460471, 2004.

[54] A. Doetzlhofer, H. Rotheneder, G. Lagger et al., "Histone deacetylase 1 can repress transcription by binding to Spl," Molecular and Cellular Biology, vol. 19, no. 8, pp. 5504-5511, 1999.

[55] S. Christakos, P. Dhawan, D. Ajibade, B. S. Benn, J. Feng, and S. S. Joshi, "Mechanisms involved in vitamin D mediated intestinal calcium absorption and in non-classical actions of vitamin D," Journal of Steroid Biochemistry and Molecular Biology, vol. 121, no. 1-2, pp. 183-187, 2010.

[56] C. R. Weber, S. C. Nalle, M. Tretiakova, D. T. Rubin, and J. R. Turner, "Claudin-1 and claudin-2 expression is elevated in inflammatory bowel disease and may contribute to early neoplastic transformation," Laboratory Investigation, vol. 88, no. 10, pp. 1110-1120, 2008.

[57] P. Dhawan, R. Ahmad, R. Chaturvedi et al., "Claudin-2 expression increases tumorigenicity of colon cancer cells: role of epidermal growth factor receptor activation," Oncogene, vol. 30, no. 29, pp. 3234-3247, 2011.

[58] M. Buchert, M. Papin, C. Bonnans et al., "Symplekin promotes tumorigenicity by up-regulating claudin-2 expression," Proceedings of the National Academy of Sciences of the United States of America, vol. 107, no. 6, pp. 2628-2633, 2010.

[59] Y.-G. Zhang, S. Wu, Y. Xia, and J. Sun, "Salmonella infection upregulates the leaky protein claudin-2 in intestinal epithelial cells," PLoS ONE, vol. 8, no. 3, Article ID e58606, 2013.

[60] P. J. Morin, "Claudin proteins in human cancer: promising new targets for diagnosis and therapy," Cancer Research, vol. 65, no. 21, pp. 9603-9606, 2005.

[61] F. Wang, B. Daugherty, L. L. Keise et al., "Heterogeneity of claudin expression by alveolar epithelial cells," American Journal of Respiratory Cell and Molecular Biology, vol. 29, no. 1, pp. 6270, 2003.

[62] S. Amasheh, T. Schmidt, M. Mahn et al., "Contribution of claudin-5 to barrier properties in tight junctions of epithelial cells," Cell and Tissue Research, vol. 321, no. 1, pp. 89-96, 2005.

[63] C. Rahner, L. L. Mitic, and J. M. Anderson, "Heterogeneity in expression and subcellular localization of claudins 2, 3, 4, and 5 in the rat liver, pancreas, and gut," Gastroenterology, vol. 120, no. 2, pp. 411-422, 2001.

[64] Z. Xuan and M. Q. Zhang, "From worm to human: bioinformatics approaches to identify FOXO target genes," Mechanisms of Ageing and Development, vol. 126, no. 1, pp. 209-215, 2005.

[65] T. Furuyama, T. Nakazawa, I. Nakano, and N. Mori, "Identification of the differential distribution patterns of mRNAs and consensus binding sequences for mouse DAF-16 homologues," Biochemical Journal, vol. 349, no. 2, pp. 629-634, 2000.

[66] S. Y. Chung, W. C. Huang, C. W. Su et al., "FoxO6 and PGC-1 $\alpha$ form a regulatory loop in myogenic cells," Bioscience Reports, vol. 33, no. 3, Article ID e00045, pp. 485-500, 2013.

[67] M. Trojanowska, "Ets factors and regulation of the extracellular matrix," Oncogene, vol. 19, no. 55, pp. 6464-6471, 2000.

[68] A. D. Sharrocks, "The ETS-domain transcription factor family," Nature Reviews Molecular Cell Biology, vol. 2, no. 11, pp. 827-837, 2001.

[69] T. L. Tootle and I. Rebay, "Post-translational modifications influence transcription factor activity: a view from the ETS superfamily," BioEssays, vol. 27, no. 3, pp. 285-298, 2005.
[70] P. Oettgen, R. M. Alani, M. A. Barcinski et al., "Isolation and characterization of a novel epithelium-specific transcription factor, ESE-1, a member of the ets family," Molecular and Cellular Biology, vol. 17, no. 8, pp. 4419-4433, 1997.

[71] A. Cabral, D. F. Fischer, W. P. Vermeij, and C. Backendorf, "Distinct functional interactions of human Skn-1 isoforms with Ese-1 during keratinocyte terminal differentiation," The Journal of Biological Chemistry, vol. 278, no. 20, pp. 17792-17799, 2003.

[72] S. P. Reddy, H. Vuong, and P. Adiseshaiah, "Interplay between proximal and distal promoter elements is required for squamous differentiation marker induction in the bronchial epithelium. Role for ESE-1, Sp1, and Ap-1 proteins," Journal of Biological Chemistry, vol. 278, no. 24, pp. 21378-21387, 2003.

[73] J.-P. Babeu and F. Boudreau, "Hepatocyte nuclear factor 4-alpha involvement in liver and intestinal inflammatory networks," World Journal of Gastroenterology, vol. 20, no. 1, pp. 22-30, 2014.

[74] G. Giebisch, R. M. Klose, and E. E. Windhager, "Micropuncture study of hypertonic sodium chloride loading in the rat," The American Journal of Physiology, vol. 206, pp. 687-693, 1964.

[75] D. E. C. Cole and G. A. Quamme, "Inherited disorders of renal magnesium handling," Journal of the American Society of Nephrology, vol. 11, no. 10, pp. 1937-1947, 2000.

[76] S. C. Hebert, "Calcium and salinity sensing by the thick ascending limb: a journey from mammals to fish and back again," Kidney International, Supplement, vol. 66, no. 91, pp. S28-S33, 2004.

[77] J. Hou and D. A. Goodenough, "Claudin-16 and claudin-19 function in the thick ascending limb," Current Opinion in Nephrology and Hypertension, vol. 19, no. 5, pp. 483-488, 2010. 


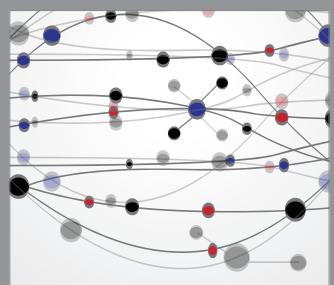

The Scientific World Journal
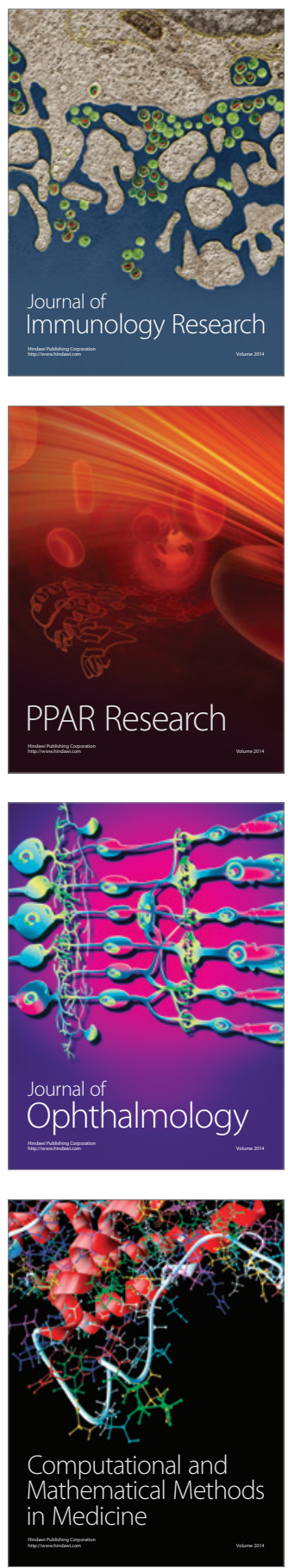

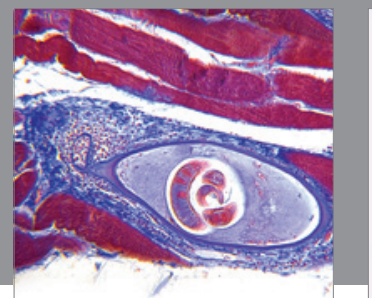

Gastroenterology

Research and Practice
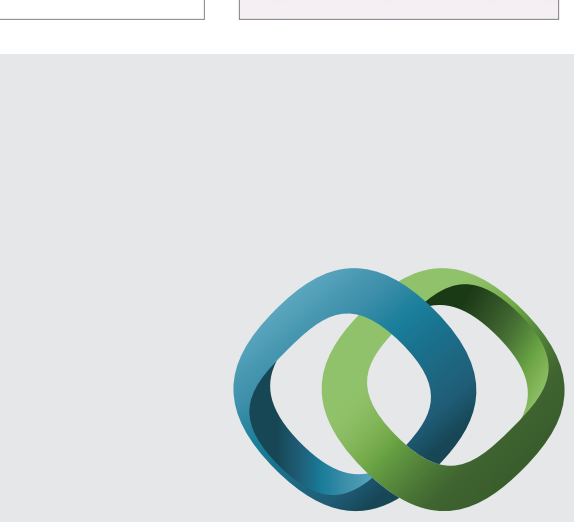

\section{Hindawi}

Submit your manuscripts at

http://www.hindawi.com
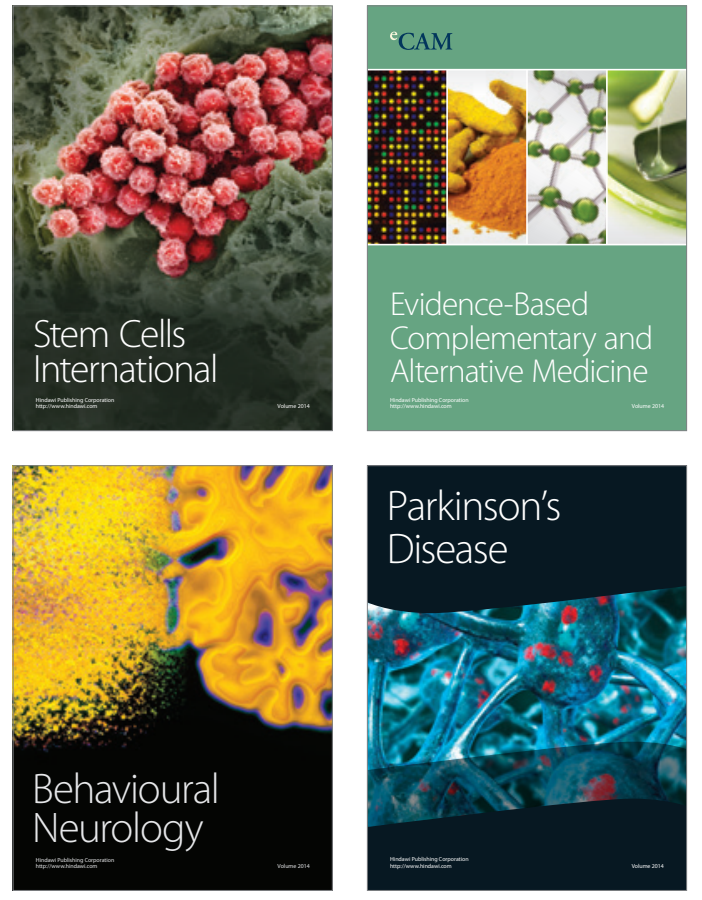
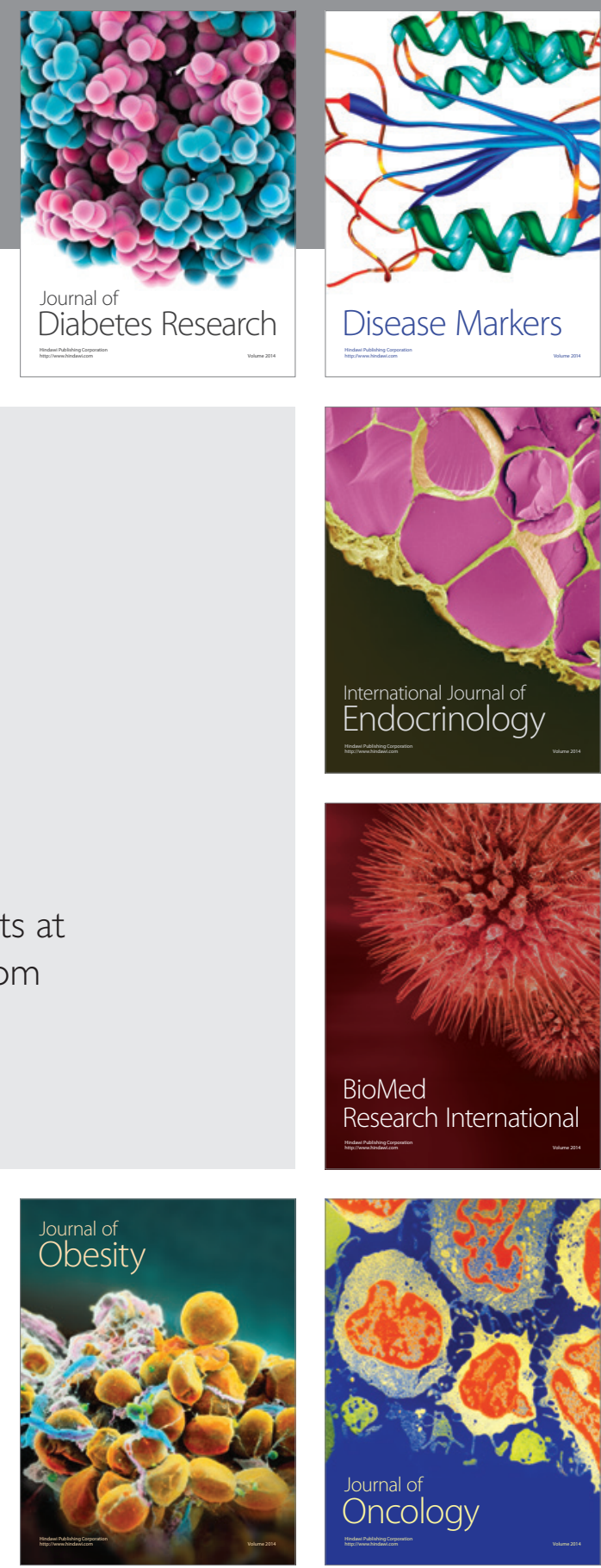

Disease Markers
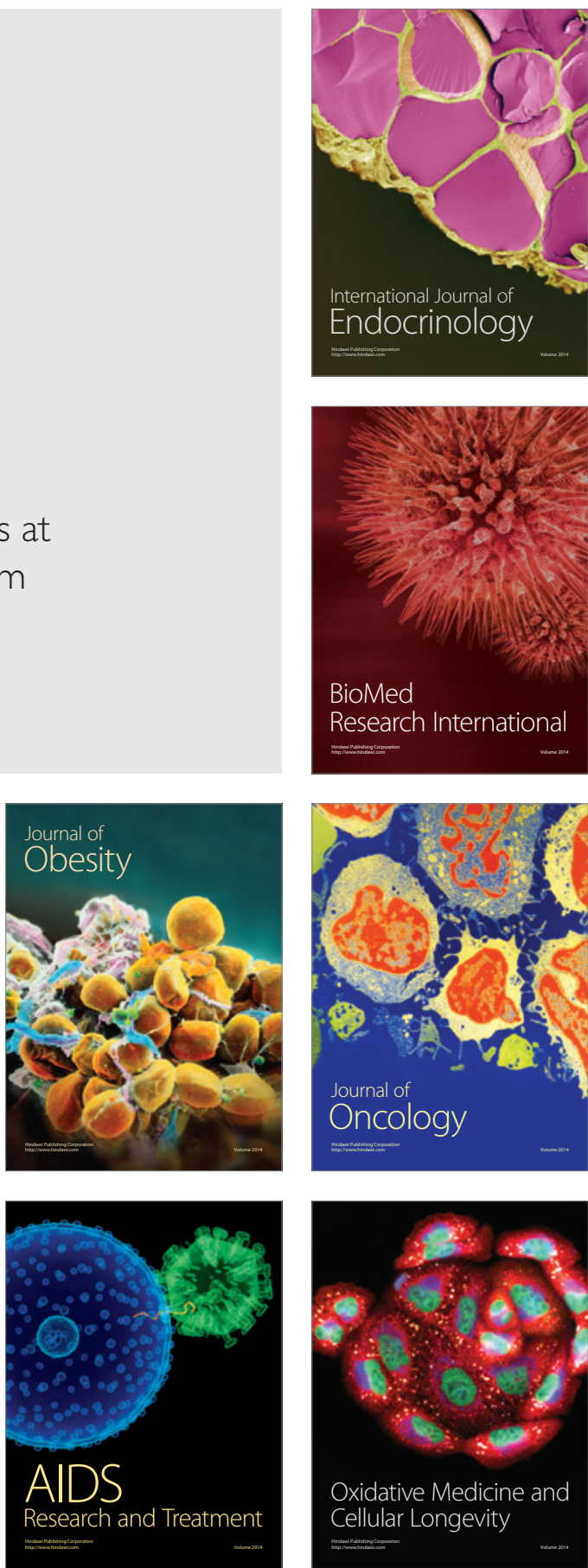